\title{
A Cross-Sectional Overview: The Effect of the Covid-19 Pandemic on the Flow Rate of Orthopedic Trauma Cases in Kuwait
}

\author{
Saleh Alsaifi ${ }^{1}$, Ahmad Boskandar ${ }^{* 2}$, Saleh Alkhaldi ${ }^{3}$, Aliaa Khaja ${ }^{4}$, Meshal Alhadhoud \\ ${ }^{1}$ Department of Orthopedics, Al-Razi Hospital, Kuwait; salsaifi@gmail.com \\ ${ }^{2}$ Department of Orthopedics, Al-Razi Hospital, Kuwait; Ahmadbouskandar@gmail.com \\ ${ }^{3}$ Department of Orthopedics, Mubarak Al-Kabeer Hospital, Kuwait; Dr_khaldi@hotmail.com \\ ${ }^{4}$ Department of Orthopedics, Al-Razi Hospital, Kuwait; aliaa.khaja@gmail.com \\ ${ }^{5}$ Department of Orthopedics, Al-Adan Hospital, Kuwait; maalhadhoud@gmail.com
}

*Corresponding author: Dr. Ahmad Boskandar; ahmadbouskandar@gmail.com

Received: 26 October 2020;

Accepted: 20 November 2020;

Published: 01 December 2020

\begin{abstract}
Objective: The COVID-19 pandemic has led many countries to carry out a range of restrictions ranging from social distancing rules to full national lockdowns. The main aim of this study was to compare the flow rates of orthopaedic trauma injuries in Kuwait prior to the partial lockdown and during the curfew period. Method: Patient records for 641 isolated traumatic orthopedic injuries were collected pre and post the nationwide enforced partial curfew. The data was collected from the registries of 3 major orthopedic centers in the country. These hospitals cover a total of about 5 million people. Results: Hospitals of Kuwait received 356 patients in March-April of 2019 and 285 in the same months of 2020 during the curfew period. A slight decrease in the flow of orthopedic injuries was noted in the curfew period, but not a statistically significant one. Male to female ratio remained the same for both groups as well as the ratio for age groups. Femur fractures in the 2020 group were slightly higher and spine fractures were slightly lower than they were in 2019. Conclusion: A slight decrease in the number of patients who had orthopedic traumatic injuries was noted during the COVID-19 enforced partial curfew period. The decreased rate however, was not statistically significant.
\end{abstract}

Keywords: Covid-19, orthopedic trauma, curfew, hospital flow-rate

\section{Introduction}

Coronavirus is one of the pathogens that primarily target the respiratory system, infamously known for its high infection rate ${ }^{[1]}$. In late December 2019, specifically in Wuhan, Hubei province in China, a coronavirus outbreak was declared and was given the name of 2019 Novel Coronavirus (COVID-19) by the World health Organization (WHO), which is caused by SARS-COV2 virus ${ }^{[1-2]}$. In January 2020, 7734 cases in China and 90 other cases from different countries have been reported ${ }^{[3]}$. The main route of spreading infection is by human-to-human transmission via direct contact or through droplets spread by coughing or sneezing from infected individuals ${ }^{[4]}$. There has been no definite treatment yet for the COVID-19 infection therefore, extensive measures have been established to prevent person-to-person transmission to control the outbreak ${ }^{[5-6]}$. Of these measures, social distancing has proven by far the most beneficial way to tackle this pandemic ${ }^{[7-8]}$. This led many countries to apply drastic curfews and total lockdowns ${ }^{[9-10]}$.
The State of Kuwait lays in the Middle East, Asia. The population is about 5 million. An overwhelming $70 \%$ of its population are expacts ${ }^{[11-12]}$. The orthopedic trauma burden outweighs the facilities available ${ }^{[12]}$. However, since the corona pandemic, the Kuwaiti authorities have taken serious and strict measures in an attempt to reduce the spread of the disease by early suspension of all schools, institutes, colleges and universities from the $12^{\text {th }}$ of March 2020. This had further burdened the orthopedic public services in the country. Quick efforts were made to efficiently restructure the system of all orthopedic departments. Elective surgeries were cancelled and the work force was dedicated to only provide orthopedic trauma, life and limb saving procedures and oncology services. To protect the staff and patients, emergency departments across the nation had been instructed to refer all isolated surgical orthopedic injuries to the only tertiary hospital available in Kuwait. The concept was to transfer all orthopedic cases from primary and secondary care centers to a tertiary center. The rationale behind this was to adapt the concept of eccentric 
patient management for those with orthopedic injuries and did not need a multi-disciplinary approach to manage their care.

Since many of the primary and secondary healthcare facilities were converted to Covid-19 buildings and isolated from other departments, it was crucial to protect orthopedic patients from any potential risks of infection.

The outpatient departments have restricted to a single surgeon per clinic, and a single clinic per specialty per day. A 12hour partial curfew was applied from 23rd of March 2020 until further notice. Certain areas in the country with high incidence of COVID-19 infections been under complete lockdown and private hospitals were suspended from receiving patients and operating. This has all been in adherence with the WHO universal COVID recommendations.

The aim of this study was to investigate the flow rate of traumatic orthopedic injuries in light of the COVID-19 pandemic in Kuwait with the inflicted curfew. In addition, the authors explore red flags in the newly structured system of orthopedic departments in the nation.

\section{Methods}

To conduct this study, the numbers of orthopedic traumatic cases were collected from three out of five orthopedics departments in Kuwait. A total of 641 patient records were obtained. The data was collected over a period of 1 month (March -April) in 2019 and 2020. Two sets of data were collected, to compare the flow-rate of traumatic orthopedic cases before and after the enforcement of the partial 12-hour a day curfew in Kuwait. The first set was collected from the 23rd of March 2019 until 23rd of April 2019, a year before the curfew enforcement. The second set was taken from the 23rd of March 2020 until 23rd of April 2020 during the curfew period.
Both sets of data were collected from the emergency department registries and filtered for orthopedic trauma cases. The data was further stratified according to age, gender, place of injury and anatomical location.

\section{Results}

In this study, the information of 645 patients was collected in precurfew period and during the curfew. $71.3 \%$ of the patients were male, while $28.7 \%$ were female. The majority of patients $(67.9 \%)$ were between 13 - 55 years old, $21.5 \%$ were older than 55 and only $10.6 \%$ were between $0-12$ years old.

The average age of the patients was 38.55 with a standardized deviation of 21.13. The youngest patient was 1 year old, while the oldest person with orthopaedic injury was 93 years old.

AlRazi orthopaedic hospital had the most numbers of patients with orthopaedic injuries (43.7\%), while AlAdan hospital came in second place with $39.2 \%$.

In addition, information about the type of injuries was collected. Table 1 shows that Femur (16.02\%), Ankle (12.38\%) and Spine $(12.11 \%)$ injuries are among the most common types of injuries. In Figure 1, the frequency of each type of injury in each hospital before and during curfew is visualized.

Around $60 \%$ of all patients in pre-curfew and during the curfew were non-Kuwaitis (Figure 2). Curfew seemed to have significant effect on decreasing the outdoor orthopaedic injuries among Non-Kuwaitis ( $\mathrm{OR}=0.499,95 \%$ CI $0.316-0.787)$. While a decrease in outdoor injuries is observed among Kuwaitis, however, this decrease is not statistically significant $(\mathrm{OR}=1.274$, $95 \%$ CI $0.739-2.194)$.

Table 1: Descriptive Statistics of demographic variables including frequency and percentage (Bold Numbers: highest rank)

\begin{tabular}{|c|c|c|c|c|c|c|}
\hline \multirow[t]{2}{*}{ Demographics } & \multicolumn{2}{|c|}{ Pre-Curfew } & \multicolumn{2}{|c|}{ Curfew } & \multicolumn{2}{|l|}{ Total } \\
\hline & Count & $\%$ & Count & $\%$ & Count & $\%$ \\
\hline \multicolumn{7}{|l|}{ Age } \\
\hline \multicolumn{7}{|l|}{ Range $=92$} \\
\hline \multicolumn{7}{|l|}{ Minimum $=1$} \\
\hline \multicolumn{7}{|l|}{ Maximum $=93$} \\
\hline \multicolumn{7}{|l|}{ Mean $=38.55$} \\
\hline \multicolumn{7}{|l|}{$\mathrm{SD}= \pm 21.13$} \\
\hline $0-12$ & 32 & 9.2 & 35 & 12.3 & 67 & 10.6 \\
\hline $13-55$ & 246 & 70.5 & 184 & 64.8 & 430 & 67.9 \\
\hline$>55$ & 71 & 20.3 & 65 & 22.9 & 136 & 21.5 \\
\hline \multicolumn{7}{|l|}{ Hospital } \\
\hline AlAdan & 156 & 44.1 & 97 & 33.3 & 253 & 39.2 \\
\hline AlRazi & 134 & 37.9 & 148 & 50.9 & 282 & 43.7 \\
\hline Mubarak & 64 & 18.1 & 46 & 15.8 & 110 & 17.1 \\
\hline \multicolumn{7}{|l|}{ Gender } \\
\hline Female & 100 & 28.2 & 85 & 29.2 & 185 & 28.7 \\
\hline Male & 254 & 71.8 & 206 & 70.8 & 460 & 71.3 \\
\hline \multicolumn{7}{|l|}{ Type of Injury } \\
\hline FEMUR & 52 & 12.8 & 67 & 19.9 & 119 & 16.02 \\
\hline TIBIA +/- FIBULA & 49 & 12.1 & 35 & 10.4 & 84 & 11.31 \\
\hline ANKLE & 51 & 12.6 & 41 & 12.2 & 92 & 12.38 \\
\hline PATELLA & 13 & 3.2 & 8 & 2.4 & 21 & 2.83 \\
\hline PELVIS & 15 & 3.7 & 18 & 5.3 & 33 & 4.44 \\
\hline HUMERUS & 36 & 8.9 & 40 & 11.9 & 76 & 10.23 \\
\hline FOREARM & 50 & 12.3 & 36 & 10.7 & 86 & 11.57 \\
\hline CLAVICLE & 14 & 3.4 & 6 & 1.8 & 20 & 2.69 \\
\hline
\end{tabular}




\begin{tabular}{|c|c|c|c|c|c|c|}
\hline SCAPULLA & 5 & 1.2 & 6 & 1.8 & 11 & 1.48 \\
\hline SPINE & 54 & 13.3 & 36 & 10.7 & 90 & 12.11 \\
\hline FOOT & 42 & 10.3 & 28 & 8.3 & 70 & 9.42 \\
\hline TENDO ACHELLIS & 8 & 2.0 & 0 & 0.0 & 8 & 1.08 \\
\hline HAND & 2 & 0.5 & 5 & 1.5 & 7 & 0.94 \\
\hline CUT WOUNDS & 15 & 3.7 & 10 & 3.0 & 25 & 3.36 \\
\hline SOFT TISSUE & 0 & 0.0 & 1 & 0.3 & 1 & 0.13 \\
\hline \multicolumn{7}{|l|}{ Place of Injury } \\
\hline Home & 128 & 39.0 & 122 & 51.0 & 250 & 44.1 \\
\hline Outdoors & 200 & 61.0 & 117 & 49.0 & 317 & 55.9 \\
\hline \multicolumn{7}{|l|}{ Nationality } \\
\hline Non-Kuwaiti & 212 & 60.2 & 177 & 60.5 & 389 & 60.5 \\
\hline Kuwaiti & 140 & 39.8 & 114 & 39.2 & 254 & 39.5 \\
\hline
\end{tabular}

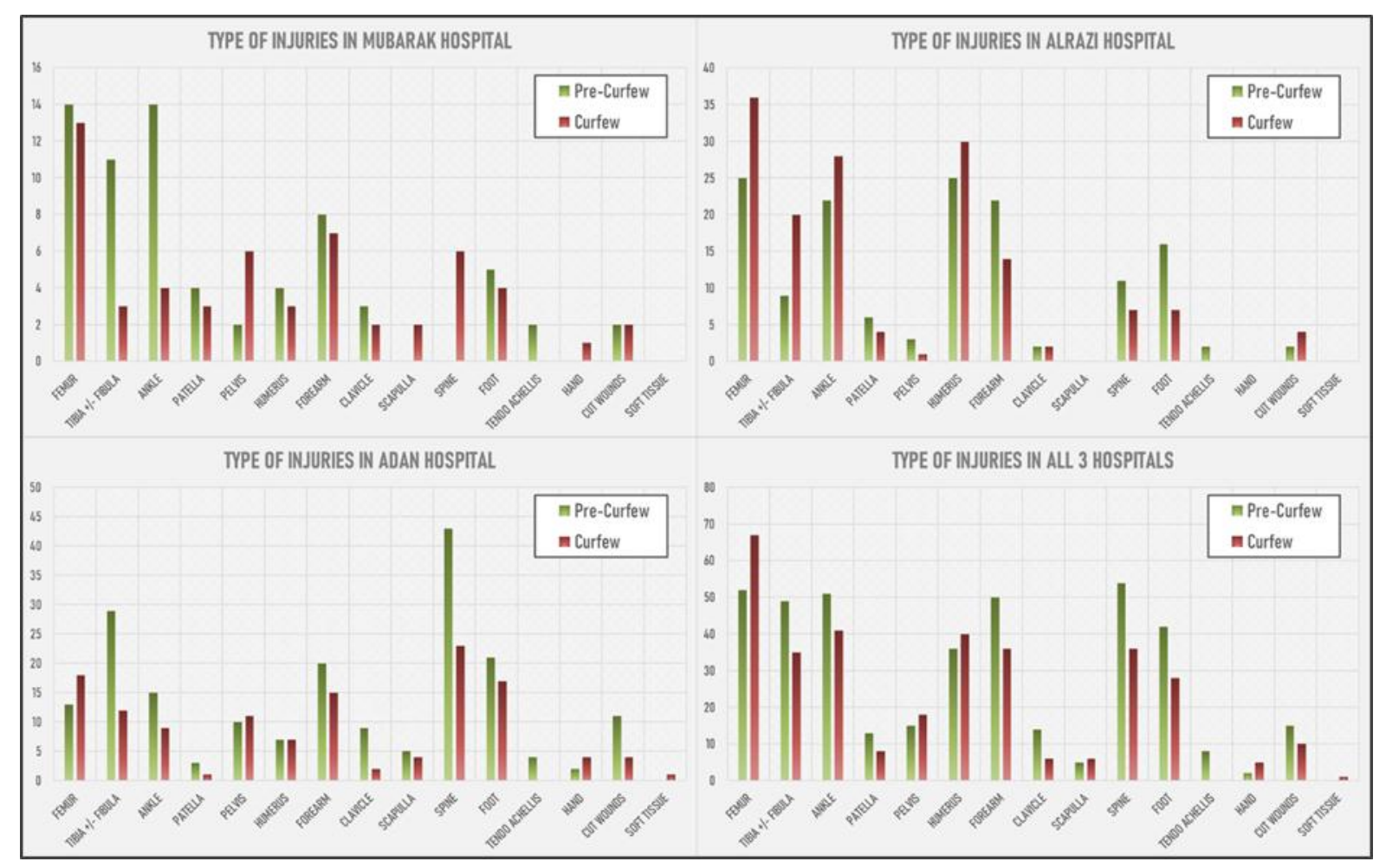

Figure 1: Visualisation of types of orthopaedic injuries in each hospital participated in this study before and during the curfew.

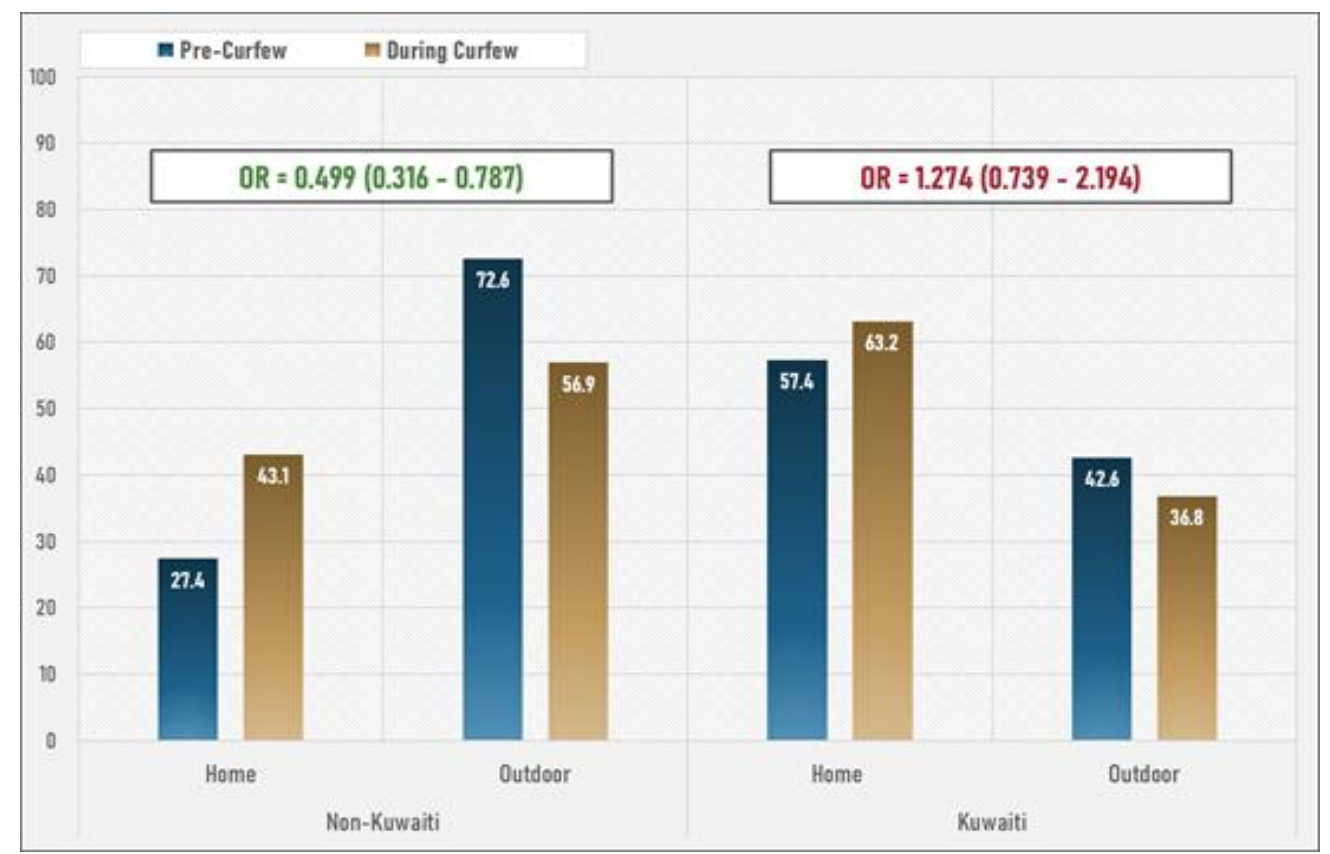

Figure 2: Visualisation of nationality vs. Home/Outdoor injury in pre-curfew and during the curfew. 


\section{Inferential Results}

A binomial logistic regression was performed to ascertain the effects of age, gender and Curfew on the likelihood that individuals in Kuwait experienced an orthopaedic injury. The data was also examined for the presence of outliers by calculating standardized residuals. No standardized residual was observed to be higher than \pm 2 , hence, all data is kept in the analysis (Table 2).

The logistic regression model was statistically significant, $\chi 2(5)=216.875, p<0.001$. The model explained 43\% (Nagelkerke R2) ${ }^{[13]}$ of the variance in the place of injury (Home/Outdoors) and correctly classified $56 \%$ of cases. In addition, Homser and Lemeshow Test ${ }^{[14]}$ was performed to measure how well the model fits the data. The results showed $\chi 2(5)=3.245, \mathrm{p}=0.662$. The $\mathrm{p}$ value was larger than 0.05 in this test, indicating that the model is not fitting the data poorly. The results indicated that all predictor variables were statistically significant: age, gender and Curfew (Time of Injury). For the purpose of simplicity, the calculated odds ratios are illustrated in a forest plot (Figure 3). Confidence intervals that include zero are not statistically significant.

Table 2: Binary Logistic Regression with Place of Injury (Home vs. Outdoors) as outcome variable and Age, Gender, Time of injury and Interaction variable (Gender*Time of injury) as predictor variables

\begin{tabular}{|c|c|c|c|c|c|}
\hline Variables & $\chi^{2}$ Wald & p value & OR & \multicolumn{2}{|c|}{$95 \% \mathrm{CI}$} \\
\hline \multicolumn{6}{|l|}{ Age } \\
\hline $0-12$ & 0.521 & 0.470 & 1.341 & 0.604 & 2.977 \\
\hline $13-55$ & 69.220 & 0.000 & 9.981 & 5.805 & 17.162 \\
\hline$>55$ & 89.062 & 0.000 & \multicolumn{3}{|l|}{ Reference } \\
\hline \multicolumn{6}{|l|}{ Gender } \\
\hline Female & \multirow[t]{2}{*}{32.282} & \multirow[t]{2}{*}{0.000} & 0.170 & 0.092 & 0.313 \\
\hline Male & & & \multicolumn{3}{|l|}{ Reference } \\
\hline \multicolumn{6}{|l|}{ Time of Injury } \\
\hline 2019 & \multirow[t]{2}{*}{3.931} & \multirow[t]{2}{*}{0.047} & \multicolumn{3}{|l|}{ Reference } \\
\hline 2020 (Curfew) & & & 0.614 & 0.380 & 0.994 \\
\hline Gender * Time of Injury & 0.149 & 0.700 & 1.213 & 0.455 & 3.236 \\
\hline
\end{tabular}

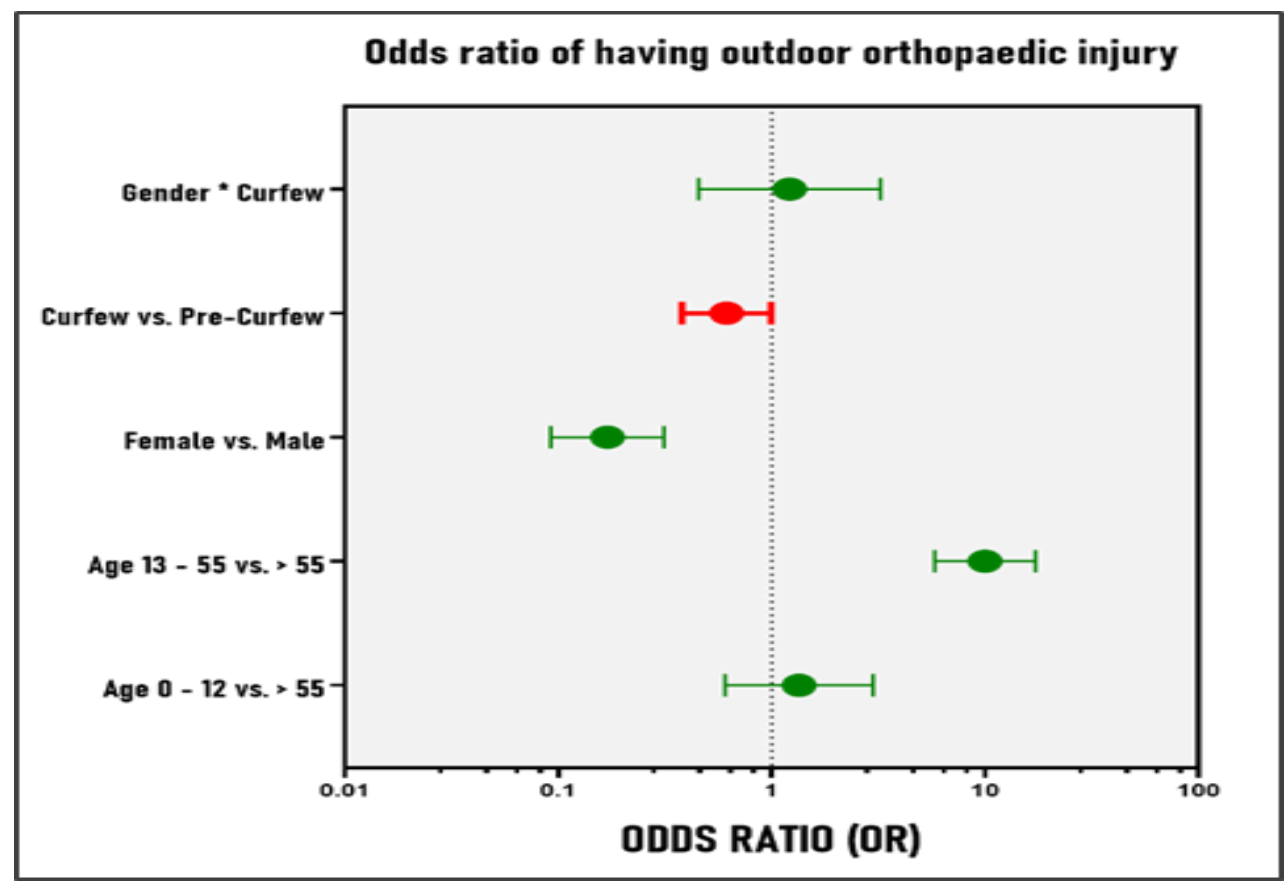

Figure 3: Forest plot illustrating odds ration calculated by binary logistic regression - Odds ratios whose confidence interval does not include 1, are statistically significant. Red interval is the main predictor (the effect of curfew).

\section{Overall Effect of Gender \& Age}

The odds ratio of outdoor injuries among females vs. males is $0.170(95 \%$ CI $0.092-0.313)$, which means that in general, in Kuwait, there have been significantly higher outdoor orthopaedic injuries among males than females. In this study, $77 \%$ of home injuries happened for females, while $70 \%$ of outdoor injuries occurred among men. According to the results, the odds of Age group $13-55$ to have outdoor orthopaedic injuries is 9.9 times higher than age group older than 55 (95\% CI $5.801-17.162)$. As shown in Figure 3, Age groups $0-12$ and $>55$ both are injured more frequently at home than outdoors, hence, their odds are not significantly different from each other $(\mathrm{OR}=1.341,95 \%$ CI 0.604 www.ijirms.in
- 2.977). This is understandable, because both age groups spend much more of their time at home than age group $13-55$.

\section{Effect of Curfew}

As the results of Table 2 indicates, the odds ratio of outdoor injuries during curfew period (2020) vs. pre-curfew period (2019) is 0.614 (95\% CI $0.380-0.994)$. The confidence interval and Wald-test results indicated that Curfew had statistically significant effect on lowering the outdoor orthopaedic injuries $(\chi 2=3.931, \mathrm{p}=$ 0.047). Figure 4 clearly indicates that while $61 \%$ of injuries have been recorded to be an outdoor injury in the pre-curfew period, only $49 \%$ of cases were due to outdoors injuries during the curfew 
(Table 1). As mentioned in binary logistic regression, this decrease is statistically significant.

Although, both curfew and gender separately have a significant effect on whether the most orthopaedic injuries occur indoors or outdoors, but their interaction is according to the performed logistic regression not statistically significant $(\mathrm{OR}=$ $1.213,95 \%$ CI $0.455-3.236$ ). Figure 5 also illustrates that the ratio of female: male remains more or less the same in pre-curfew and during the curfew period.

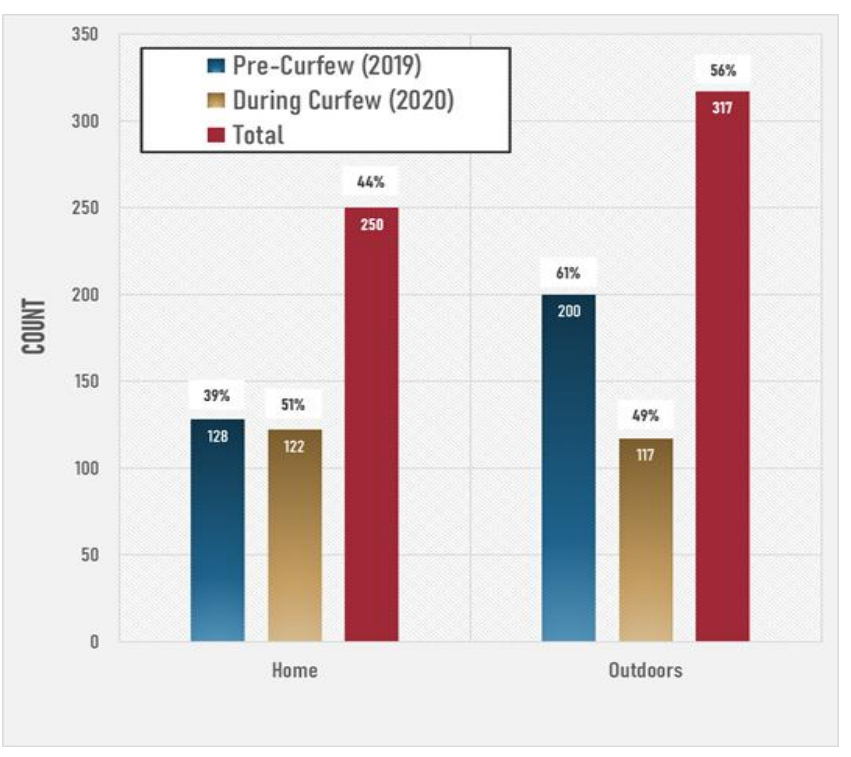

Figure 4: Visualization of Home/Outdoors Orthopaedic injuries in pre-curfew and during curfew period

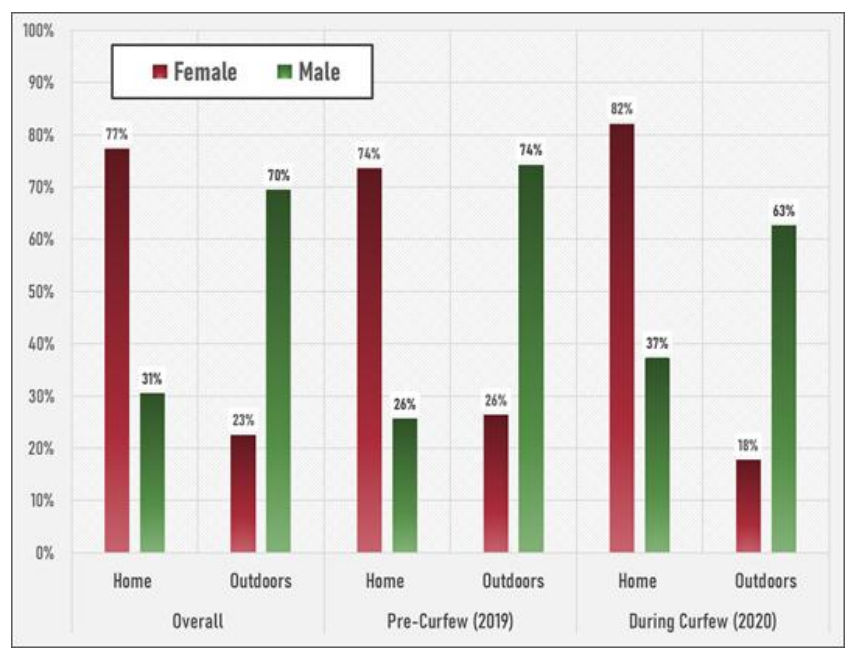

Figure 5: Visualisation of interaction between Gender \& Curfew variable and their effect on place of orthopaedic injury

\section{Discussion}

The Covid-19 pandemic has left nations with a high toll of hardships in the field of medicine. Curfews and lockdowns on entire countries have shifted medical practice away from elective surgeries. With the focus on urgent care, orthopedic surgeons in Kuwait found themselves in front of uncertainty with the rapid change of structures in hospital management and leadership. To the authors' knowledge, the literature does not specify how lockdowns and curfews have impacted the number of patients acquiring traumatic orthopedic injuries. Although this is a cross-sectional study, the scarcity in the literature on this particular topic is perceived as strength. This study will give the medical community insight on how we practice and lead in medicine proactively, especially in dynamic circumstances. It also gives insight on the effect of curfews on social behavior and how it resonates on orthopedic surgery practice.

This study compared two snapshots in a time before curfews and a time during curfews in the orthopedic emergency departments. Although it is clear that the influx of orthopedic injuries in Kuwait has decreased, reasons behind this are unclear. For instance, it is difficult to know whether patients due to curfew restrictions face difficulties getting to hospitals or it is related to their inability to work or resume their daily living activities ${ }^{[5]}$. There is yet to be answers to these questions, however, this study offers some insight on the current situation in Kuwait regarding orthopedic injuries. Healthcare systems worldwide are facing challenges that they have never dealt with before ${ }^{[15-16]}$. In this study, we had lower numbers of the elderly population presenting to our departments. There has been concern over the medical vulnerability of this group and reason to believe that neglect or lack of support is a major attribution ${ }^{[17-20]}$.

From this study, it has been ascertained that during the curfew period, the male: female ratio of orthopedic trauma admissions was $3: 1$. Yet, in Nepal, the male: female ratio is $1: 1$ during their lockdown period ${ }^{[19]}$. Although they did not compare the flow rate of their patients, they did report similar restructuring methods with elective surgeries and hospital management. The same can be said for the United States of America, India, Germany, Spain, Singapore and Malaysia ${ }^{[21-26]}$. They are abiding by the WHO guidelines as well as Kuwait's Ministry of health and orthopedic community. Some countries reported a similar response to transferring orthopedic patients to tertiary centers ${ }^{[21,24]}$ away from potential Covid-19 hazard risks. While on the other hand, other countries did not have the leverage of doing so ${ }^{[21,22,24]}$.

Exact numbers on how many traumatic orthopedic injuries these countries are receiving were not found. However, some studies have reported that most of orthopedic injuries were due to simple falls and slippages at home ${ }^{[24-25]}$. This correlates with our observations, that half of the cases that presented to our orthopedic departments happened at home.

\section{Limitations}

This study was intended as a preliminary observation. A major limitation in this study was the ability to collect data. In a country where this type of information is not computerized, manual collection was done across hospitals. Not all hospitals granted permission to access their registries. The authors also understand that the time period for the comparable groups are relatively short. However, the analysis was needed urgently, to address possible deficiencies in the current system and prepare for protocols according to the new traumatic pattern manifestations implicated by the curfew imposed. Another challenge for this study was collecting data regarding ethnicity, income and educational level and co-morbidities. However, at this point in time this information has proven to be difficult to obtain.

\section{Conclusion}

The Covid-19 pandemic has created new challenges for the orthopedic departments in Kuwait. Following the WHO guidelines has been effective. A lower number of orthopedic departments have been recorded during the partial 12-hour curfew but they were not significant. There is no reason to instigate new changes to the current Covid-19 orthopedic department structure. 


\section{Conflict of Interest}

None

\section{Financial Funding}

Non

\section{References}

[1] H. Lu, C.W. Stratton, Y.W. Tang, Outbreak of pneumonia of unknown etiology in wuhan China: the mystery and the miracle, J. Med. Virol. 92 (4) (2020) 401-402.

[2] R. Lu, X. Zhao, J. Li, P. Niu, B. Yang, H. Wu, et al., Genomic characterisation and epidemiology of 2019 novel coronavirus: implications for virus origins and receptor binding, Lancet 395 (10224) (2020) 565-574.

[3] W.G. Carlos, C.S. Dela Cruz, B. Cao, S. Pasnick, S. Jamil, Novel wuhan (2019-nCoV) coronavirus, Am. J. Respir. Crit. Care Med. 201 (4) (2020) 7-8.

[4] W. Wang, J. Tang, F. Wei, Updated understanding of the outbreak of 2019 novel coronavirus (2019-nCoV) in Wuhan, China, J. Med. Virol. 92 (4) (2020) 441-447.

[5] Masters PS, Perlman S. Coronaviridae. In: Knipe DM, Howley PM, eds. Fields virology. 6th ed. Lippincott Williams \& Wilkins, 2013:825-58.

[6] Armstrong GL, MacCannell DR, Taylor J, et al. Pathogen genomics in public health. N Engl J Med 2019;381:2569-2580.

[7] Tan WJ, Zhao X, Ma XJ, et al. A novel coronavirus genome identified in a cluster of pneumonia cases Wuhan, China 2019-2020. China CDC Weekly 2020;2:61-62.

[8] Liu GS, Li H, Zhao SC, Lu RJ, Niu PH, Tan WJ. Viral and bacterial etiology of acute febrile respiratory syndrome among patients in Qinghai, China. Biomed Environ Sci 2019;32:438-445.

[9] Katarzyna Kotfis, Shawniqua Williams Roberson, Jo Ellen Wilson, Wojciech Dabrowski, Brenda T. Pun, E. Wesley Ely. (2020) COVID-19: ICU delirium management during SARS-CoV-2 pandemic. Critical Care 24:1.

[10] Li Tan, Qi Wang, Duanyang Zhang, Jinya Ding, Qianchuan Huang, Yi-Quan Tang, Qiongshu Wang, Hongming Miao. (2020) Lymphopenia predicts disease severity of COVID-19: a descriptive and predictive study. Signal Transduction and Targeted Therapy 5:1.

[11] Shafiq MO et al., The journey of orthopaedic surgery from residency to fellowship: A cross-sectional study in the Gulf Cooperation Council countries, Journal of Taibah University Medical Sciences, 2019.02.005.

[12] Alhendi B, Al-Saifi S, Khaja A. Medical tourism overseas: a challenge to Kuwait's healthcare system. Int J Travel Med Glob Health. 2020;8(1):22-30.

[13] Cox, D.R. and E.J. Snell (1989) Analysis of Binary Data. Second Edition. Chapman \& Hall.
[14] Hosmer, David W.; Lemeshow, Stanley (2013). Applied Logistic Regression. New York: Wiley. ISBN 978-0470-58247-3.

[15] Pradhan, N., Acharya, B., Devkota, P., Gyawali, B., Bhatta, T., Pokhrel, P., Thakur, A., Shrestha, A., \& Shrestha, S. (2020). Orthopaedic services during COVID-19 lockdown at Patan Hospital, Nepal. Journal of Patan Academy of Health Sciences, 7(1), 19-24.

[16] O'Connor CM, Anoushiravani AA, DiCaprio MR, Healy WL, Iorio R, Economic Recovery Following the COVID-19 Pandemic: Resuming Elective Orthopaedic Surgery and Total Joint Arthroplasty, The Journal of Arthroplasty (2020), doi: https://doi.org/10.1016/j.arth.2020.04.038.

[17] Ashford, R. U., Nichols, J. S., \& Mangwani, J. (2020). Annotation: The COVID-19 pandemic and clinical orthopaedic and trauma surgery. Journal of Clinical Orthopaedics and Trauma. doi:10.1016/j.jcot.2020.04.002.

[18] Sahu, D., Agrawal, T., Rathod, V., \& Bagaria, V. (2020). Impact of COVID 19 lockdown on orthopaedic surgeons in India: A survey. Journal of Clinical Orthopaedics and Trauma. doi:10.1016/j.jcot.2020.05.007.

[19] Yadav, S. K., Khatana, S., \& Kumar, A. (2020). Re: Covid-19 and ortho and trauma surgery: The Italian experience. Injury. doi:10.1016/j.injury.2020.04.034.

[20] Chang LZ, Wang W, Murphy D, Po HJH. Novel Coronavirus and Orthopaedic Surgery: Early Experiences from Singapore. J Bone Joint Surg Am. 2020;20. doi: 10.2106/JBJS.20.00236.

[21] Guo X, Wang J, Hu D, Wu L, Gu L, Wang Y, et al. The Orthopaedic Forum Survey of COVID-19 Disease among Orthopaedic Surgeons in Wuhan, People's Republic of China. J Bone Joint Surg. 2020:1-15.

[22] de Caro, F., Hirschmann, T.M. \& Verdonk, P. Returning to orthopaedic business as usual after COVID-19: strategies and options. Knee Surg Sports Traumatol Arthrosc (2020). https://doi.org/10.1007/s00167-02006031-3.

[23] Konda, Sanjit R et al. "COVID-19 Response in the Global Epicenter: Converting a New York City Level 1 Orthopedic Trauma Service into a Hybrid Orthopedic and Medicine COVID-19 Management Team.” Journal of orthopaedic trauma, 10.1097.

[24] Enrique Gómez-Barrena, Juan C Rubio-Suárez, Nicomedes Fernández-Baillo, Samuel Antuña, Ana CruzPardos, Manuel Blanco, Eduardo Ortiz-Cruz, Gaspar González-Morán, Enrique Gil-Garay, Limiting spread of COVID-19 in an orthopaedic department-a perspective from Spain, Journal of Surgical Case Reports 2020, Issue 4. doi.org/10.1093/jscr/rjaa095

[25] Graichen, H. (2020). The role of an Orthopaedic Surgeon in the time of Covid-19 Pandemic-a German perspective. Journal of Orthopaedics, 19, A1-A3.

[26] Farrell, Sarah et al. "Recommendations for the Care of Pediatric Orthopaedic Patients During the COVID-19 Pandemic." The Journal of the American Academy of Orthopaedic Surgeons vol. 28,11 (2020): e477-e486. 